\title{
Preparation and Identification of Some New Pyridinium Salts
}

\author{
Ameer M. Shaker and Mehdi S. Shihab* \\ Department of Chemistry, College of Science, Al-Nahrain University, Baghdad-Iraq. \\ * Corresponding Author:mehdi_shihab@yahoo.com
}

\begin{abstract}
In this work the pyridinium salts were prepared by two stage. The first step was preparation of Schiff bases compounds (A1-A5), The second step is preparation of pyridinium salts (B1-B5) by Nalkylation reaction between Schiff bases compounds and a proper alkyl halide(1,2-Chloroethane, 1bromopropane, benzyl chloride, benzyl chloride andbromoethane). All the compounds were confirmed their structures by using spectroscopic techniques (FTIR and ${ }^{1} \mathrm{HNMR}$ ).
\end{abstract}

[DOI: $10.22401 /$ ANJS.22.4.03]

Keywords: Schiff base compounds, Pyridinium Salt, FTIR, HNMR.

\section{Introduction}

Pyridine and its synthesized derivatives are important chemical compounds with huge direction of applications in the various fields.3-nicotinaldehyde is a pyridine derivative found in the liquid phase, it is useful starting material to obtain a precursor and followed steps to obtain target molecules. Enormous reports on synthesis of heterocyclic derivatives containing $\mathrm{S}, \mathrm{O}$ and Natoms have been listed to have abroad spectrum of biological activity. Numerous data concerning synthesis of heterocyclic have been reported [1-3]. Pyridinium salts have a kind of positively charged surfactants that have a hydrophilic fragment, polar chemical environment, and a hydrophobic side that can be interred into nonpolar chemical molecular mass. Aromatic ring heterocyclic derivatives in addition to different groups of function can be presented either on $\mathrm{N}$ atom or on the pyridine rings. A considerable attention pay for pyridinium compounds that tested with their pharmacological and biological activities. They have importance in their antimicrobials [4-9] antivirals [10-12] anti-hypertension and immune stimulate activities [13]. Some of pyridinium derivatives of aldoximehaveeffectiveness antidote against poisoning of organophosphate [14]. In the present work, we prepared some pyridinium salts by preparation of Schiff base compounds and N-alkylation reaction with alkyl halides. All the compounds were confirmed their structures by using spectroscopic techniques (FTIR and ${ }^{1}$ HNMR).

\section{Experimental part.}

\subsection{Synthesis of Schiff base compounds} (A1-A5).

The Schiff base compounds was prepared according to the following procedure: An ethanolic solution of nicotinaldehyde $(0.005 \mathrm{~mol})$ was added to an ethanolic solution of a proper amine $(0.005 \mathrm{~mol})$. Then $(10 \%$ $\mathrm{NaOH}, 0.3 \mathrm{~mL}$ ) was added to the solution and refluxed for 4-6 hrs. After concentration of the solution, the precipitate was separated, filtered, washed with ethanol. Finally, the yield was recrystallized from ethanol. The physical properties of compounds (A1-A5) are shown in Table (1). 
<smiles>[R]N=Cc1cccnc1</smiles>

nicotinaldehyde

(A1-A5)

R-NH : $_{2}$ O-Tulodin . 2-Chloroaniline . Benzylamine . 4-Aminoacetophenone . 4-Bromo-2-methylaniline

Table (1)

Physical properties of compounds (A1-A5).

\begin{tabular}{||l|l|c||c||c|c|}
\hline & \multicolumn{1}{|c|}{ Name of compound } & $\begin{array}{c}\text { Chemical } \\
\text { Formula }\end{array}$ & Color & $\begin{array}{c}\text { M.P. } \\
\mathbf{0} \text { C }\end{array}$ & $\begin{array}{c}\text { Yield } \\
\text { (\%) }\end{array}$ \\
\hline \hline A1 & $\begin{array}{l}\text { 1-(pyridin-3-yl)-N-(o- } \\
\text { tolyl)methanimine (A1) }\end{array}$ & $\mathrm{C}_{13} \mathrm{H}_{10} \mathrm{~N}_{2}$ & $\begin{array}{c}\text { Pale } \\
\text { brown }\end{array}$ & $150-153$ & 79 \\
\hline \hline A2 & $\begin{array}{l}\text { N-(2-chlorophenyl)-1-(pyridin-3-yl) } \\
\text { methanimine(A2) }\end{array}$ & $\mathrm{C}_{12} \mathrm{H}_{9} \mathrm{ClN}_{2}$ & Black & $135-138$ & 70 \\
\hline \hline A3 & $\begin{array}{l}\text { N-benzyl-1-(pyridin-3- } \\
\text { yl)methanimine (A3) }\end{array}$ & $\mathrm{C}_{13} \mathrm{H}_{12} \mathrm{~N}_{2}$ & Yellow & $116-120$ & 76 \\
\hline \hline A4 & $\begin{array}{l}\text { 1-(4-((pyridin-3-ylmethylene)amino) } \\
\text { phenyl)ethan-1-one (A4) }\end{array}$ & $\mathrm{C}_{14} \mathrm{H}_{12} \mathrm{~N}_{2} \mathrm{O}$ & Yellow & $129-133$ & 87 \\
\hline \hline A5 & $\begin{array}{l}\text { N-(4-bromo-2-methylphenyl)-1- } \\
\text { (pyridin-3-yl)methanimine (A5) }\end{array}$ & $\mathrm{C}_{13} \mathrm{H}_{11} \mathrm{BrN}_{2}$ & Gray & $145-149$ & 76 \\
\hline
\end{tabular}

\subsection{Synthesis of Pyridinium salts (B1-B5):}<smiles>[R]N=Cc1cccnc1</smiles>

(A1-A5)

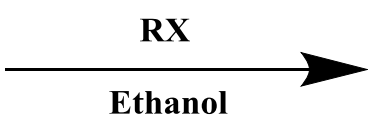

RX: Benzyl chloride. 1-Bromopropane . 1,2-dichloroethane . . Bromoethane
A mixture of $(0.01 \mathrm{~mol})$ Schiff base product(A1-A5) and $(0.01 \mathrm{~mol})$ of a proper alkyl halide (1,2-Chloroethane, 1bromopropane, benzyl chloride, benzyl chloride and bromoethane) in $10 \mathrm{~mL}$ of acetonitrile was allowed to stand 12 hours at room temperature. Then, the mixture was refluxed for 6 hrs. The final product (B1-B5) was filtered, washed with acetonitrile and dried. The physical properties of compounds (B1-B5) are shown in Table (2). 
Table (2)

Physical properties of compounds (B1-B5).

\begin{tabular}{|c|c|c|c|c|c|}
\hline & Name of compound & $\begin{array}{l}\text { Chemical } \\
\text { Formula }\end{array}$ & Color & $\begin{array}{c}\mathrm{M.P} . \\
{ }^{\circ} \mathrm{C}\end{array}$ & $\begin{array}{c}\text { Yield } \\
(\%)\end{array}$ \\
\hline B1 & $\begin{array}{l}\text { 1-propyl-3-((o- } \\
\text { tolylimino)methyl)pyridiniumbromide }\end{array}$ & $\mathrm{C}_{16} \mathrm{H}_{19} \mathrm{BrN}_{2}$ & $\begin{array}{c}\text { Off } \\
\text { white }\end{array}$ & 300dec. & 80 \\
\hline B2 & $\begin{array}{l}\text { 1-benzyl-3-((benzylimino)methyl)pyridinium } \\
\text { chloride }\end{array}$ & $\mathrm{C}_{20} \mathrm{H}_{19} \mathrm{ClN}_{2}$ & Orange & $223-228$ & 71 \\
\hline B3 & $\begin{array}{l}\text { 3-(((4-acetylphenyl)imino)methyl)-1-(2- } \\
\text { chloroethyl)pyridinium chloride }\end{array}$ & $\mathrm{C}_{16} \mathrm{H}_{16} \mathrm{Cl}_{2} \mathrm{~N}_{2} \mathrm{O}$ & Brown & 230dec. & 79 \\
\hline B4 & $\begin{array}{l}\text { 3-(((4-bromo-2- } \\
\text { methylphenyl)imino)methyl)-1- } \\
\text { ethylpyridinium bromide }\end{array}$ & $\mathrm{C}_{15} \mathrm{H}_{16} \mathrm{Br}_{2} \mathrm{~N}_{2}$ & White & $120-124$ & 75 \\
\hline B5 & $\begin{array}{l}\text { 3-(((2-chlorophenyl)imino)methyl)-1- } \\
\text { ethylpyridinium bromide }\end{array}$ & $\mathrm{C}_{14} \mathrm{H}_{14} \mathrm{BrClN}_{2}$ & White & $165-169$ & 64 \\
\hline
\end{tabular}

\section{Results and Discussion.}

The present work was included new pyridinium salt derivatives (B1-B5) Through usual preparation methods by converting nicotinaldehyde to Schiff base compounds (A1-A5), and followed by preparing pyridinium salts (B1-B5) by reaction the Schiff base compounds with a proper alkyl halide (1,2-chloroethane, 1-bromopropane, benzyl chloride, benzyl chloride and bromoethane). All the compounds were confirmed their structures by using spectroscopic techniques. In general, the characteristic stretching bonds of FTIR spectra to Schiff base compounds (A1-A5) are $(\mathrm{C}=\mathrm{N})$ bonds. The stretching $(\mathrm{C}=\mathrm{N})$ bonds of the compounds (A1-A5) within the range (1650$\left.1620 \mathrm{~cm}^{-1}\right)$ with disappearing $(\mathrm{C}=\mathrm{O})$ bond of nicotinaldehyde. There are others characteristic stretching bonds, as (C-H) aromatic bond at $\left(3100-3000 \mathrm{~cm}^{-1}\right)[15]$. Table(3) show the spectral data of IR for compounds (A1-A5). In general, the characteristic stretching bonds of FTIR spectra data of pyridinium salts (B1-B5) are (C-H) aromatic bond at $\left(3100-3000 \mathrm{~cm}^{-1}\right)$ and $(\mathrm{C}-\mathrm{H})$ aliphatic bond at $\left(3000-2850 \mathrm{~cm}^{-1}\right)$ [15] Table(4) is show FTIR spectral data for prepared compounds (B1-B5). The ${ }^{1} \mathrm{HNMR}$ spectra of the pyridinium salt derivatives (B1B5) show that aliphatic and aromatic hydrogen $(\mathrm{C}-\mathrm{H})$ in different chemical shift positions [15] and that's confirmed structure of derivatives (B1- B5) (solvent $\left(\mathrm{D}_{2} \mathrm{O}\right)$ ) Table (5) and Figure (1) are shown ${ }^{1} \mathrm{H}-\mathrm{NMR}$ spectral data of derivatives (B1- B5).

Table (3)

FTIR spectral data for prepared compounds (A1-A5).

\begin{tabular}{|c|c|c|c|c|c|}
\hline $\begin{array}{c}\text { Comp. } \\
\text { No. }\end{array}$ & $\begin{array}{c}\vee \mathrm{C}-\mathrm{H} \\
\text { aromatic }\end{array}$ & $\begin{array}{c}V \mathrm{C}-\mathrm{H} \\
\text { aliphatic }\end{array}$ & $\begin{array}{l}\vee \mathrm{C}=\mathrm{C} \\
\text { aromatic }\end{array}$ & $v \mathrm{C}=\mathrm{O}$ & $v \mathrm{C}=\mathrm{N}$ \\
\hline A1 & 3021 & 2916 & $\begin{array}{l}1575 \\
1483\end{array}$ & - & 1628 \\
\hline A2 & 3059 & - & $\begin{array}{l}1581 \\
1477\end{array}$ & - & 1631 \\
\hline A3 & 3055 & 2950 & $\begin{array}{l}1582 \\
1478\end{array}$ & - & 1641 \\
\hline A4 & 3035 & 2885 & $\begin{array}{l}1589 \\
1475\end{array}$ & $1724(\mathrm{C}=\mathrm{O})$ & 1631 \\
\hline A5 & 3032 & 2949 & $\begin{array}{l}1564 \\
1475 \\
\end{array}$ & - & 1625 \\
\hline
\end{tabular}


Table (4)

FTIR spectral data for prepared compounds (B1-B5).

\begin{tabular}{|c||c||c||c||c||c||}
\hline Comp.No. & $\begin{array}{c}\boldsymbol{v} \text { C-H } \\
\text { aromatic }\end{array}$ & $\begin{array}{c}\boldsymbol{v} \text { C-H } \\
\text { aliphatic }\end{array}$ & $\begin{array}{c}\boldsymbol{v} \text { C=C } \\
\text { aromatic }\end{array}$ & $v$ C=O & $v$ C=N \\
\hline \hline B1 & 3078 & 2978 & 1593 & - & 1635 \\
\hline B2 & 3032 & 2924 & 1612 & - & 1635 \\
\hline B3 & 3047 & 2985 & 1612 & 1743 & 1630 \\
\hline B4 & 3025 & 2924 & 1579 & - & 1631 \\
\hline B5 & 3020 & 2978 & 1616 & - & 1639 \\
\hline
\end{tabular}

Table (5)

${ }^{1} \mathrm{H}$-NMR spectral data of derivatives (B1- B5) in ppm.

\begin{tabular}{|c|c|c|}
\hline Comp.No. & Compound structure & ${ }^{1} \mathrm{H}-\mathrm{NMR}$ data of $(\delta-\mathrm{H})$ in ppm \\
\hline B1 & & $\begin{array}{l}4 \mathrm{H} \text { of pyridine-ring }(8.7-9.2) ; 4 \mathrm{H} \text { of } \\
\text { phenyl- rings }(7.2-8.7), 2 \mathrm{H} \text { of }-\mathrm{CH}_{2}- \\
\mathrm{N}^{+} \text {group }(5.0) ; 1 \mathrm{H} \text { of imine }(8.3) ; 1.0- \\
2.5 \text { of } 5 \mathrm{H} \text { of aliphatic; } 3 \mathrm{H} \text { of methyl } \\
\text { group }(2.2)\end{array}$ \\
\hline B2 & & $\begin{array}{l}4 \mathrm{H} \text { of pyridine-ring }(8.7-9.5) ; 10 \mathrm{H} \text { of } \\
\text { phenyl- rings }(7.3-8.7), 2 \mathrm{H} \text { of }-\mathrm{CH}_{2} \text {-ph } \\
(5.9) ; 1 \mathrm{H} \text { of imine }(8.3) ; 4.3 \text { of } 2 \mathrm{H} \text { of } \\
\text { aliphatic amine }\end{array}$ \\
\hline B3 & & $\begin{array}{l}4 \mathrm{H} \text { of pyridine-ring }(8.7-9.0) ; 4 \mathrm{H} \text { of } \\
\text { phenyl- rings }(6.9-8.7), 2 \mathrm{H} \text { of }-\mathrm{CH}_{2-} \\
\mathrm{N}^{+}(4.7) ; 1 \mathrm{H} \text { of imine }(8.3) ; 2.5 \text { of } 3 \mathrm{H} \text { of } \\
\text { aliphatic; } 1.7 \text { of } 2 \mathrm{H} \text { of aliphatic-halide }\end{array}$ \\
\hline B4 & & $\begin{array}{l}\mathrm{H} \text { of } \mathrm{CH}=\mathrm{N}-(8.3) ; 4 \mathrm{H} \text { of pyridine-ring } \\
(8.7-9.4) ; 3 \mathrm{H} \text { of phenyl- rings }(6.8-7.6) \text {, } \\
2 \mathrm{H} \text { of }-\mathrm{CH}_{2} \text { group }(4.7) ; 1.0-1.53 \mathrm{H} \text { of } \\
\text { aliphatic; } 2.5 \text { of } 3 \mathrm{H} \text { of methyl-ph }\end{array}$ \\
\hline B5 & & $\begin{array}{l}\mathrm{H} \text { of } \mathrm{CH}=\mathrm{N}-(8.3) ; 4 \mathrm{H} \text { of pyridine-ring } \\
(8.7-9.4) ; 4 \mathrm{H} \text { of phenyl- rings }(6.8-7.6) \text {, } \\
2 \mathrm{H} \text { of }-\mathrm{CH}_{2} \text { group }(4.7) ; 1.0-1.53 \mathrm{H} \text { of } \\
\text { aliphatic }\end{array}$ \\
\hline
\end{tabular}




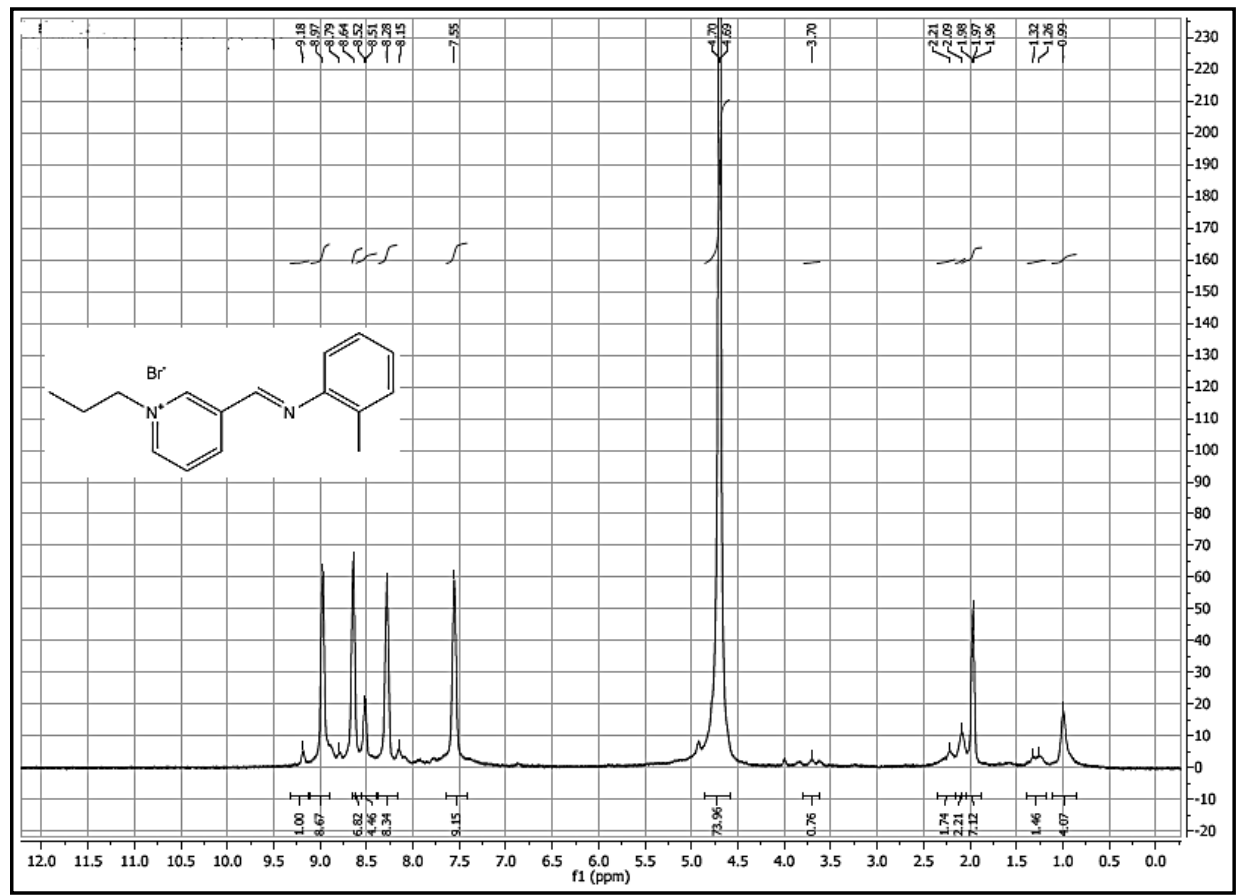

Fig.(1): ${ }^{1}$ HNMR for compound (B1).

\section{Conclusion:}

Some pyridinium salts derivatives (B1-B5) were prepared by known chemical steps included imine formation then formation of pyridinium salt by Menschutkin reaction. The chemical structure of prepared compounds was confirmed using spectroscopic techniques and determined their physical properties.

\section{Acknowledgements:}

The project was supported by Al-Nahrain University.

\section{References}

[1] Sharma S., Gangal S., Rauf A., green chemistry approach to the sustainable advancement to the synthesis of heterocyclic chemistry, J. Chem., 1 (4), 693- 717, 2008.

[2] Oliver O., Controlled Microwave Heating in Modern Organic Synthesis Chem., Angew. Chem. Int. Ed., 43, 6250 -6284, 2004.

[3] Thorsteinsson T., Masson M., Kristinsson G., Hjalmarsdottir M. A., Hilmarsson H., Poziomek E. J., Hackley. E., Steinberg G. E., Microwave-assisted Quaternization of Various Pyridine Derivatives and their Antibacterial Activity, Croat. Chem. Acta., 90(3), 425-433, 2017.
[4] El-Hiti G., Alotaibi M., Ahmed A., Hamad B., Ahmed D., Ahmed A., Hashim H., Yousif E., The Morphology and Performance of Poly (Vinyl Chloride) Containing Melamine Schiff Bases against Ultraviolet Light, Molecules 24 (4), 803, 2019.

[5] Mavel S., Renou J. L., Galtier C., Snoeck R., Andrei, J. Balzarini G., De Clercq E., Gueiffier A., Arzneimittel forschung. Synthesis of Imidazo [1,2-a] pyridine Derivatives as Antiviral Agents, 51(2), 304309, 2001.

[6] Bernardino A. M. R., Pinheiro L. C. S., Ferreira V. F., Azevedo A. R., synthesis and antiviral activity of new4- (phenylamino) thieno [2,3-b]pyridine derivatives, Heterocycl. Commun., 10(6), 407-410, 2004.

[7] Saleh A. Bahshwan1, Atef M. Amer and Ahmed A. Fayed, Synthesis and Pharmacological Activities of Some Thieno Pyridazine Derivatives Using 5-Amino-4Ethoxycarbonyl Phenanthro [9,10-e] Theino [2,3-c] Pyridazine as a Starting Material , J. Am. Sci. 6(2), 151-159, 2010.

[8] Stojiljković M. P., Jokanović M., Rada. T., Pyridinium Oximes: Rationale for Their Selection as Causal Antidotes Against Organophosphate Poisonings and Current 
Solutions for Auto-Injectors.57(4), 435443, 2006.

[9] Gašo-Sokač D., Katalinić M., Kovarik Z., Bušić V., Kovač S., Synthesis and evaluation of novel analogues of vitamin B6 as reactivators of tabun and paraoxon inhibited acetylcholinesterase. Chem-Biol Interact. 187(1), 234-237, 2010.

[10] Busic V., Pavlović H., Roca S., VikićTopić D., Gašo-Sokač D., Microwaveassisted Quaternization of Various Pyridine Derivatives and their Antibacterial Activity, Croatica Chemica Acta. 90 (3), 425-433, 2017.

[11] Free M. L. Corros. Sci. Understanding the effect of surfactant aggregation on corrosion inhibition of mild steel in acidic medium 44 (12), 2865-2870, 2002.

[12] Sp^inu C., Pleniceanu M., Tigae C., Biologically Active Transition Metal Chelates with a 2Thiophenecarboxaldehyde-Derived Schiff Base: Synthesis, Characterization, and Antibacterial Properties, Turk. J. Chem., 32, 487 - 493, 2008.

[13] Shaalan N., Laftah N., El-Hiti G.A., Alotaibi M.H., Muslih R., Ahmed D. S., Yousif E., Poly(vinyl Chloride) Photostabilization in the Presence of Schiff Bases Containing a Thiadiazole Moiety. Molecules, 23, 913, 2018.

[14] Brown B., Christopher S. Foote, Brent L. Iverson, Eric Anslyn, Organic Chemistry, 6th Edition, Brooks Cole, 2011.

[15] Coates J., John Wiley pp. \& Sons Ltd, Chichester, "Interpretation of Infrared Spectra, A Practical Approach, in Encyclopedia of Analytical Chemistry, R.A. Meyers (Ed.)", 10815-10837, 2000. 